\title{
Avaliação da qualidade higiênico-sanitária da água de poços rasos localizados em uma área urbana: utilização de colifagos em comparação com indicadores bacterianos de poluição fecal*
}

\author{
The evaluation of the hygienic and sanitary quality of water from private shallow wells \\ situated in an urban area of south-eastern Brazil: a comparison between the use of \\ coliphages and bacterian indicators of fecal pollution
}

\section{Luiz Augusto do Amaral ${ }^{* *}$, Oswaldo Durival Rossi Júnior**, Antonio Nader Filho*, Alba Valéria Alexandre ${ }^{* \star *}$}

\begin{abstract}
AMARAL, L.A. do et al. Avaliação da qualidade higiênico-sanitária da água de poços rasos localizados emumaáreaurbana: utilização de colifagos em comparação com indicadores bacterianos de poluição fecal. Rev. Saúde Pública, 28: 345-8, 1994. Foram submetidas às contagens de colifagos, coliformes totais, coliformes fecais e de estreptococos fecais, 104 amostras de água colhidas de 8 poços rasos localizados na área urbana do Município de Jaboticabal, SP, Brasil, com a finalidade de avaliar as condições higiênicosanitárias e de verificar as correlações existentes entre o número de colifagos e o de bactérias indicadoras de poluição fecal. Os resultados obtidos evidenciaram a ocorrência de $96(92,3 \%)$ amostras fora dos padrões bacteriológicos de potabilidade estabelecidos pelo Ministério da Saúde, monstrando ser precárias as condições higiênico-sanitárias das águas analisadas. Os achados evidenciaram a inexistência de correlação entre o número de colifagos e os números de bactérias indicadoras de poluição fecal.
\end{abstract}

Descritores: Critérios de qualidade da água. Colifagos, isolamento. Contaminação bacteriológica da água.

\section{Introdução}

Na periferia da área urbana, as águas subterrâneas oriundas de poços rasos constituem-se importantes fontes de suprimento de água para consumo humano e animal. Tradicionalmente, esse tipo de fonte de abastecimentoé considerado seguropara oconsumo "in natura"25.

Sworobuck e col. ${ }^{22}$ (1987) citam que dependendo da capacidade filtrante do solo as águas subterrâneas podem se apresentar livres de contaminação, sendo, portanto, seguras como fonte de água para o consumo. Por outro lado, os referidos autores afirmam que lençóis aquáticos de pouca profundidade são influenciados pela água que percola da superfície e portanto sujeitos à contaminação.

A poluição fecal da água de poços rasos é facilita-

* Pesquisa subvencionada pela Fundação de Amparo à Pesquisa do Estado de São Paulo/FAPESP (Processo $n^{\circ}$ 92/0444-8).

** Departamento de Medicina Veterinária Preventiva da Faculdade de Ciências Agrárias e Veterinárias de Jaboticabal/UNESP - Jaboticabal, SP - Brasil

*** Acadêmica do curso de Medicina Veterinária. Faculdade de Ciências Agrárias e Veterinárias de Jaboticabal/UNESP - Jaboticabal, SP - Brasil

Separatas/Reprints: L.A. do Amaral - Rodovia Carlos Tonanni $\mathrm{km} 5$ - 14870-000 - Jaboticabal, SP - Brasil

Edição subvencionada pela FAPESP. Processo 94/0500-0. da pela pequena profundidade do lençol aquífero, fato este verificado por Crane e Moore ${ }^{5}$ (1984), que afirmam ser a contaminação bacteriana da água subterrânea localizada e restrita a poços que utilizam lençóis aquíferos próximos à superfície. A esse respeito, Lamka e col..$^{13}$ (1980) ressaltam a importância do controle dos suprimentos de água subterrânea privados, na prevenção de possíveis agravos à saúde dos consumidores.

Muitas vezes a presença de microrganismos patogênicos na água é decorrente da poluição por fezes humanas e de animais, provenientes de águas residuárias urbanas e rurais ${ }^{10}$. A esse respeito, Craun e $\mathrm{McCabe}^{6}$ (1973) relatam que nos Estados Unidos, no período de 1946 a 1970, 71\% dos surtos de doenças transmitidas pela água resultaram da contaminação de sistemas individuais de abastecimento, sendo que $57 \%$ desses surtos foram devido ao uso de água subterrânea não tratada.

Em decorrência do fato de que os microrganismos patogênicos usualmente aparecem de forma intermitente e em baixo número na água, pode-se pesquisar outros grupos de microrganismos que coexistem com os patogênicos nas fezes. Desse modo, a presença desses microrganismos na água constitui indicador de poluição fecal, principalmente os originários do homem e de animais de sangue quente ${ }^{1}$.

Os coliformes totais, coliformes fecais e estreptococos fecais podem ser utilizados como indicadores de poluição fecal na água ${ }^{3}$. Todavia, existem autores que 
afirmam que a pesquisa dessas bactérias não se constitui bomindicadorde contaminaçãodaáguaporvírusentéricos ${ }^{3}$, 26

Os bacteriófagos, devido a sua morfologia, estrutura e composição, apresentam comportamento semelhante aos vírus entéricos na água ${ }^{8,21}$. Os colifagos são os bacteriófagos mais utilizados como indicadores de poluição fecal na água, em decorrência da correlação existente entre estes e as bactérias coliformes, nesse ambiente ${ }^{1}$.

Entretanto, o conhecimento regionalizado da relação entre colifagos e coliformes totais, coliformes fecais e outros indicadores de poluição fecal tradicionais é importante, no sentido de poder utilizar-se esses microrganismos como indicadores ${ }^{7}$.

O presente trabalho tem por objetivos conhecer a qualidade higiênico-sanitária e verificar a relação existente entre os colifagos e as bactérias utilizadas como indicadores de poluição fecal na água de poços rasos situados na área urbana.

\section{Material e Método}

Foram submetidas à análise 13 amostras de água de cada um dos 8 poços rasos, escolhidos por sorteio entre os poços rasos cadastrados na área urbana do Município de Jaboticabal, Estado de São Paulo, perfazendo um total de 104 amostras analisadas.

As amostras foram colhidas e transportadas ao laboratório, de acordo com as recomendações do Standard Methods for Examination of Water and Wastewater ${ }^{1}$.

Para a determinação dos números de coliformes totais, coliformes fecais e de estreptococos fecais, foi empregada a técnica da membrana filtrante, utilizando-se como meios de cultura o M-ENDO ÁGAR, MFC-ÁGAR e o KF Streptococcus Ágar, respectivamente ${ }^{1}$.

A determinação do número de colifagos e o preparo da cultura hospedeira de Escherichia coli C (ATCC $n^{\circ} 13.706$ ) foram realizados de acordo com as técnicas recomendadas pela APHA $^{1}$ (1985).

Para a pesquisa da presença de colifagos também foi utilizada como bactéria hospedeira a Escherichia coli C (ATCC 13.706) e a técnica empregada foi a preconizada por Wentsel e col. ${ }^{23}$ (1982).

Para verificar a existência de correlação entre os resultados das análises microbiológicas, foi aplicada a análise de regressão linear e, para a comparação entre médias, o teste $F^{16}$.

\section{Resultados e Discussão}

Observa-se, na Tabela 1, a inexistência de correlação entre os números de colifagos e os indicadores de poluição fecal pesquisados nas amostras de água dos
Tabela 1 - Coeficientes de correlação entre os números de coliformes totais, coliformes fecais de estreptococos fecais e de colifagos nas amostras de água de seis poços rasos*

\begin{tabular}{llccccc}
\hline & \multicolumn{5}{c}{ Poços } \\
\cline { 2 - 6 } Correlações & 1 & 2 & 3 & 4 & 5 & 6 \\
\hline Coliformes totais & & & & & \\
x Colifagos & $0,42^{\text {ns }}$ & $0,15^{\text {ns }}$ & $0,02^{\text {ns }}$ & $0,17^{\text {ns }}$ & $0,16^{\text {ns }}$ & $0,36^{\text {ns }}$ \\
Coliformes fecais & & & & & \\
$x$ Colifagos & $0,17^{\text {ns }}$ & $0,25^{\text {ns }}$ & $0,14^{\text {ns }}$ & $0,18^{\text {ns }}$ & $0,17^{\text {ns }}$ & $0,15^{\text {ns }}$ \\
Estreptococos fecais & & & & & \\
$x$ Colifagos & $0,10^{\text {ns }}$ & $0,12^{\text {ns }}$ & $0,01^{\text {ns }}$ & $0,47^{\text {ns }}$ & $0,18^{\text {ns }}$ & $0,14^{\text {ns }}$ \\
\hline
\end{tabular}

${ }^{\star}$ Nos poços 7 e 8 não foi possivel quantificar os colifagos, não sendo realizada a análise de regressão linear.

ns- Não significativo ao nivel de $5 \%$ de probabilidade

poços rasos. Este fato pode estar relacionado com o baixo nível de contaminação fecal das amostras de água analisadas, cujos valores médios máximos obtidos foram de $89,60 \mathrm{UFC} / \mathrm{ml}, 9,08 \mathrm{UFC} / \mathrm{ml}$ e 1,91 UFC/ml, para os coliformes totais, coliformes fecais e estreptococos fecais, respectivamente (Tabela 2). A esse respeito, Wiggins e Alexander ${ }^{24}$ (1981) sugerem que a densidade mínima da bactéria hospedeira para que haja replicação dos bacteriófagos é de $10^{4}$ UFC/ml, enquanto que Cornax e col. ${ }^{4}$ (1991) verificaram que em águas com números de coliformes fecais entre $10^{2}$ e $10^{4} \mathrm{UFC} / \mathrm{ml}$ a relação entre esses microrganismos e os colifagos apresentaram baixo coeficiente de regressão.

Kott $^{12}$ (1974) obteve ausência de colifagos em amostras de água de poços rasos com número de coliformes fecais que variaram de 9 a $150 \mathrm{UFC} / \mathrm{ml}$. Simkova e Cervenka ${ }^{20}$ (1981) analisando também água de poços rasos não verificaram a presença de colifagos em 406 amostras analisadas.

No presente trabalho, analisando através do teste $\mathrm{F}$, os valores das médias dos números de coliformes fecais das amostras de água em que foram detectados colifagos e os valores das médias destes microrganismos nas amostras com ausência de colifagos, verificou-se que os valores médios de coliformes fecais nas amostras positivas para colifagos foi significativamente maior $(F=35,86)$, mostrando, portanto, existir uma relação entre a presença de coliformes fecais e de colifagos.

Os dados constantes na Tabela 3 mostram que $92,12 \%$ das 104 amostras de água dos poços rasos apresentaram-se contaminadas por coliformes fecais e, portanto, em desacordo com os padrões de potabilidade estabelecidos pelo Ministério da Saú$\mathrm{de}^{14}$. Resultados semelhantes foram verificados por outros autores, que encontraram de $96 \%$ a $100 \%$ das amostras de água de poços rasos, localizados em áreas urbanas, contaminadas por coliformes fecais, evidenciando, portanto, o risco à saúde da população consumidora deste tipo de água sem nenhum tratamento ${ }^{2,9,11}$.

Observa-se, ainda na Tabela 3, que a diminuição 
Tabela 2 - Valores das médias geométricas dos números de coliformes totais, coliformes fecais, estreptococos fecais e de colifagos nas amostras de água dos 8 poços analisados.

\begin{tabular}{lcccc}
\hline Poços & $\begin{array}{c}\text { Coliformes totais } \\
\text { UFC/ml }\end{array}$ & $\begin{array}{c}\text { Coliformes fecais } \\
\text { UFC/ml }\end{array}$ & $\begin{array}{c}\text { Estreptococos fecais } \\
\text { UFC/ml }\end{array}$ & $\begin{array}{c}\text { Colifagos } \\
\text { UFP/ml }\end{array}$ \\
Poço 1 & 44,51 & 9,08 & 1,53 & 0,39 \\
Poço 2 & 88,72 & 4,33 & 1,91 & 0,01 \\
Poço 3 & 89,60 & 4,22 & 0,41 & 0,01 \\
Poço 4 & 85,30 & 1,52 & 0,64 & 0,02 \\
Poço 5 & 35,88 & 1,02 & 0,57 & 0,17 \\
Poço 6 & 30,70 & 0,77 & 0,50 & 0,13 \\
Poço 7 & 7,00 & 0,13 & 0,10 & 0,00 \\
Poço 8 & 3,20 & 0,06 & 0,08 & 0,00 \\
\hline
\end{tabular}

UFC = Unidade Formadora de Colónia.

UFP = Unidade Formadora de Placa.

Tabela 3 - Médias geométricas do número de coliformes fecais, percentagem das amostras fora do padrão e percentagem de detecção de colifagos nas amostras de água dos 8 poços rasos.

\begin{tabular}{lccc}
\hline $\begin{array}{l}\text { Ponto de } \\
\text { amostragem }\end{array}$ & $\begin{array}{c}\text { Coliformes fecais } \\
\text { UFC } / \mathrm{ml}\end{array}$ & $\begin{array}{c}\text { Amostras fora do padrão\%* } \\
(\geq, 1 \text { Coliforme fecal/100 ml) }\end{array}$ & $\begin{array}{c}\text { Detecção de colifagos } \\
\text { amostras \% }\end{array}$ \\
\hline Poço 1 & 9,08 & 100 & 100,0 \\
Poço 2 & 4,33 & 100 & 65,0 \\
Poço 3 & 4,22 & 100 & 58,0 \\
Poço 4 & 1,52 & 100 & 53,0 \\
Poço 5 & 1,02 & 100 & 42,0 \\
Poço 6 & 0,77 & 100 & 41,0 \\
Poço 7 & 0,13 & 83 & 7,7 \\
Poço 8 & 0,06 & 54 & 15,0 \\
\hline Média** & 2,64 & 92,12 & 47,71 \\
\hline
\end{tabular}

"Ministério da Saúde, 1990.

** Média aritmética.

na detecção de colifagos nas amostras de água foi acompanhada pela redução dos números médios de coliformes fecais. Tais achados coincidem com as observações de diversos autores ${ }^{8,12,15,17,18,19}$.

Verificou-se, portanto, nas condições da realização do presente trabalho, que não foi viável a utilização da presença de colifagos como indicadores de poluição fecal para o monitoramento da qualidade da água dos poços rasos analisados, baseado na ausência de coliformes fecais em $100 \mathrm{ml} \mathrm{da}$ amostra, uma vez que não foi obtida correlação entre os números de colifagos e das bactérias indicadoras de poluição fecal pequisadas. Também foi observada diminuição na detecção dos colifagos com a redução da contaminação da água por coliformes fecais, fato este que poderia levar à presença de resultados falsos negativos, o que minimizaria o risco dessas águas para a saúde da população consumidora.

\section{Agradecimento}

À Dra. Maria Ines Zanoli Sato (CETESB-SP) pelo fornecimento da cepa de Escherichia coli utilizada como hospedeira.

AMARAL, L.A. do et al. [The evaluation of the hygienic and sanitary quality of water from private shallow wells situated in an urban area of south-eastern Brazil: a comparison between the use of coliphages and bacterian indicators of fecal pollution]. Rev. Saúde Pública, 28: 345-8, 1994. One hundred and four water samples from eight private shallow wells situated in the urban area of Jaboticabal city, State of $S$. Paulo, Brazil, were submitted to coliphage, total coliform, fecal coliform and fecal streptococcus counts, for the purpose of discovering their hygienic and sanitary quality and of verifying the correlations between the coliphage numbers and the fecal pollution indicator bacteria. Ninety-six (92.3\%) of the samples were not up to the microbiological potability standards. This result demonstrates the unsatisfactory hygienic and sanitary quality of the water samples. The results show also the absence of correlations among coliphages, and the fecal pollution indicatior bacteria.

Keyworlds: Water quality criteria. Coliphagos, isolation. Bacteriological water contamination.

\section{Referências Bibliográficas}

1. AMERICAN PUBLIC HEALTH ASSOCIATION (APHA). Standard methods for the examination of water and wastewater. 16th ed. New York, 1985.

2. CARVALHO, A.C.F.B. Efeito dos cloradores simplificados sobre a qualidade bacteriológica da água de poços rasos (cisternas) na comunidade de Bom Jardim, Ibirité, M.G., Belo Horizonte, 1983. [Tese de Mestrado - Escola de Veterinária da UFMG].

3. COLWELL, R.R. Bacterial and viruses-indicator of environmental changes ocourring estuaries. Environ. Int., 1:223-31, 1978.

4. CORNAX, R.; MORINIGO, M.A.; BALEBONA, D.C.; BORREGO, J.J. Significance of several bacteriophage groups as 
indicators of sewage pollution in marine waters. Water Res., 25:673-8, 1991.

5. CRANE, S.R.L. \& MOORE, J.A. Bacterial pollution of groundwater: a review. Water, Air Soil Pollut, 22:67-83, 1984.

6. CRAUN, G.F. \& McCABE, L. Review of the causes of waterborne diseases outbreaks. J. Am. Water Work. Assoc., 1:74-84 1973.

7. DUTKA, B.J.; EL SHAARAWI, A.; MARTINS, M.T.; SANCHEZ, P. North and South American Studies on the potential of coliphage as a water quality indicator. Water Res., 21:1127-34, 1987.

8. EL-ABAGY, M.M.; DUTKA, B.J.; KAMEL, M. Incidence of coliphages in potable water supplies. Appl. Environ. Microbiol., 54: 1632-33, 1988

9. GOMES, C.L.L. \& MANDIL, A.C. Estreptococos fecais e coliformes em água de poços rasos. Rev. Esc. Eng. UFMG, (14):31-43, 1969

10. GONZALES, G.F.; TAYLOR, M.L.; ALFARO, G. Estudio bacteriológico del agua de consumo en una comunidad Mexicana. Bol. Ofic. Sanit. Panam., 93:127-41, 1982.

11. GUILLEMIN, F.; PASCALLE, H.; UWECHUE, N.; MONJOUR, L. Faecal contamination of rural water supply in the Sahelian area. Water Res., 25:923-7, 1991.

12. KOTT, Y.; ROZE, N.; SPERBER, S.; BETZER, N. Bacteriophages as viral pollution indicator. Water Res., 8:165-79, 1974.

13. LAMKA, K.G.; LeCHEVALLIER, M.W.; SEIDLER, R.J. Bacterial contamination of drinking water supplies in a modern rural Neighborhood. Appl. Environ. Microbiol., 39:734-8, 1980.

14. MINISTÉRIO DA SAÚDE. Normas e padrão de potabilidade da água destinada ao consumo humano. Brasília, 1990.

15. MORINIGO, M.A.; WHEELER; D.; BERRY, C.; JONES, C. Evaluation of different bacteriophage groups as faecal indicators in contaminated natural waters in southerEngland. Water Res., 26:267-1, 1992.

16. NETER, J. \& WASSERMAN, W. Applied linear statiscal models: regression, analysis of variance and experimental designs. Homewood, Richard D. Irwin, Inc., 1974.
17. O'KEEFE, B. \& GREEN, J. Coliphages as indicators of faecal pollution at three recreational beaches on the firth of forth Water Res., 23:1027-30, 1989.

18. PEDRO, R.N.A.; KUSSUMI, T.A.; GELLI, D.S.; KAWANO M.; SOUZA, A. Aspectos higiênico-sanitários da água de poços cavados em diferentes áreas socioeconômicas de São Paulo. Rev. Inst. Adolfo Lutz, 48:21-7, 1988.

19. RATTO, A.; DUTKA, B.J.; VEGA, C.; LOPEZ, C.; ELSHAARAWI, A. Potable water safety assesed by coliphage and bacterial tests. Water Res., 23:253, 1989.

20. SIMKOVA, A. \& CERVENKA, J. Coliphages as ecological indicators of enteroviruses in various water systems. Bull. World Health Organ., 59:61 1-8, 1981.

21. STETLER, R.E. Coliphages as indicator of enteroviruses. Appl. Environ. Microbiol., 48, 668-70, 1984.

22. SWOROBUCK, J.F.; LAW, C.B.; BISSONNETTE, G.K. Assessment of the bacteriological quality of rural ground water supplies in Northern West Virginia. Water Air Soil Pollut., 36:163-70, 1987.

23 - WENTSEL, R.S.; O'NEILL, P.E.; KITCHENS, J.F. Evaluation of coliphage detection as a rapid indicator of water quality. Appl. Environ. Microbiol., 43:430-4, 1982.

24 - WIGGINS, B.A. \& ALEXANDER, M. Minimum bacterial density of bacteriophage replication: implications for significance of bacteriophages in natural ecosystems. Appl. Environ. Microbiol., 49: 19-23, 1985.

25 - YATES, M.V.; GERBA, C.P.; KELLEY, L.M. Virus resistence in groundwater. Appl. Environ. Microbiol, 49:778-81, 1985.

26 - ZOHAR, D.; STEINHAUER, Z.; ARTZ, E.; BEN HARIN, I. Enteroviruses coliphages and indicator bacteria in various water systems. In: Enteric viruses in water. Otawa, Ed. Melnick, 1984.

Apresentado para publicação em 14.10.1994 Reapresetado em 18.7.1994 Aprovado para publicação em 11. 8. 1994 